\title{
lodine deficiency and associated factors among school children: a cross-sectional study in Ethiopia
}

\author{
Sintayehu Hailu', Mamo Wubshet ${ }^{2}$, Haile Woldie ${ }^{3}$ and Amare Tariku ${ }^{3 *}$
}

\begin{abstract}
Background: lodine deficiency remains a public health problem in the world. It is the leading cause of preventable mental retardation and brain damage worldwide. Though 12 million school age children are at risk of developing iodine deficiency, there is a scarcity of literature showing the magnitude of iodine deficiency in Ethiopia. Therefore, this study aimed to determine the prevalence and associated factors of iodine deficiency among school children in Robe District, southeast Ethiopia.
\end{abstract}

Methods: A school based cross-sectional study was conducted from February to June, 2015. A structured interviewer-administered questionnaire was used to collect data. A systematic random sampling technique was employed to select 422 children. A multivariate logistic regression analysis was carried out to identify factors associated with iodine deficiency. In the multivariate analysis, variables with a $P$-value of $<0.05$ were considered statistically significant.

Results: A total of 393 school children participated in the study. The median urinary iodine level was $78 \mu \mathrm{g} / \mathrm{l}$. About 57 and $43.5 \%$ of the children were found with low urinary iodine level and goiter, respectively. Only $29 \%$ of the households utilized adequately iodized salt. The result of the multivariate analysis revealed that the odds of iodine deficiency were higher among female $[\mathrm{AOR}=2.23 ; 95 \% \mathrm{Cl}$ : 1.54, 3.55] and older (10-12 years) $[\mathrm{AOR}=2.21$; $95 \%$ Cl: 1.44, 3.42] children.

Conclusion: In this community, the prevalence of goiter and low urine iodine level is high. Thus, iodine deficiency exists as severe public health problem. In addition, there is a low utilization of iodized salt in the setting. Therefore, it is crucial to intensify efforts in the implementation of iodized salt. Moreover, attention should be given to school children to address ID.

Keywords: Low urine iodine level, Goiter, School children, Southeast Ethiopia

\section{Background}

Iodine is an essential micronutrient for supporting different physiological functions, however its deficiency is associated with a wider range of health problems [1-3]. Iodine Deficiency (ID) is considered as the most common preventable cause of mental retardation [4], and it results in decreased resistance against infections, poor school performance, and lack of physical strength of the child [5]. Moreover, previous reports claimed that ID

\footnotetext{
*Correspondence: amaretariku15@yahoo.com

${ }^{3}$ Department of Human Nutrition, Institute of Public Health, College of Medicine and Health Sciences, University of Gondar, Gondar, Ethiopia

Full list of author information is available at the end of the article
}

causes $25 \%$ of the Disability Adjusted Life Years (DALY's) occurring in Africa [6]. As a result, it is found to significantly affect the socio-economic development of the nation at large [7]. Compared to other population segments, pregnant mothers and school children are the most vulnerable groups for ID [8].

ID is a global public health problem which is endemic in the mountainous regions of Europe, Asia, South and Central America and Eastern Africa [9]. Globally, 241 million school children are suffering from Iodine Deficiency Disorders (IDD), while more than 1.5 billion people are at risk of ID [10]. Likewise, IDD is observed among 57 million African children [10-12]. In Africa, in 
spite of its public health importance, the high burden of communicable diseases, socio-economic crisis, and political instabilities in the past have made the elimination of ID more challenging [13]. In Ethiopia, ID has remained a public health problem among school children for many decades [14-18], and the prevalence rate has reached $59.1 \%$ in Senbo District, southwest Ethiopia [19]. Also, it causes 37.3 cretins, 33.4 miscarriage, and 47.5 still births and neonatal deaths per 1000 live births [20].

ID is mainly caused by low iodine content in the diet, arising from low iodine levels in the soil, water, or crops [21]. In addition, the consumption of goiterogenic substance containing food items, like cassava and millet [22], and co-existing micronutrient deficiencies (iron, selenium and vitamin A deficiency) [23], poor household socio-economic status, low maternal education, the unavailability of latrine, advanced age and sex of the child [24-27] are some of the factors associated with ID.

Cognizant of the problem, the Government of Ethiopia has planned to eradicate ID and to achieve the utilization of adequately iodized salt to $90 \%$ by the year 2015 [28]. Furthermore, the Federal Ministry of Health designed a National Nutrition Program and micronutrient guideline, and endorsed a proclamation for ensuring the availability of iodized salt [28, 29], though significant changes have not been attained [30]. Thus, investigating the burden of ID have a paramount significance to evaluate the progress of the current interventions, however literature is dearth, particularly in the study area. Therefore to fill the knowledge gap, this study aimed to estimate the prevalence and associated factors of ID among school children (6-12 years) in Robe District, southeast Ethiopia.

\section{Methods}

\section{Study setting}

A school based cross-sectional study was conducted in Robe District from February to June, 2015. The district is found in Oromia Regional State, southeast Ethiopia, $430 \mathrm{~km}$ from the capital city of Ethiopia, Addis Ababa. Robe District is found between 2510 and $2800 \mathrm{~m}$ above sea level, and gets an average rainfall of $800-900 \mathrm{ml}$ twice a year. Administratively the district is structured into a total of three kebeles (smallest administrative unit in Ethiopia). According to the 2015 Robe District Finance and Economic Development Report, a total of 73,386 people live in the area, and women constitute $47.5 \%(37,043)$ of the total population. The district has seven government primary schools.

\section{Sample size and sampling procedure}

The required sample size for the study was determined using a single population proportion formula by considering the following assumptions: $50 \%$ expected prevalence of ID (low urinary iodine level), at a $95 \%$ confidence level, and a $5 \%$ margin of error (d). Finally, a sample size of 422 was obtained after adding a $10 \%$ non-response rate. A systematic sampling technique was employed to select the study participants. The total number of children going to each government primary school was obtained from the school director, and was divided by the total sample size to get the sampling fraction $\left(K^{\text {th }}=\mathrm{N} / \mathrm{n}\right)$. Moreover, the total number of eligible children selected from each school was proportionateto-population size.

\section{Data collection tools and procedures}

A structured interviewer-administered questionnaire was used to collect data. The questionnaire was constructed in three major sections, socio-demographic and economic variables, and health and feeding pattern related characteristics. A total of seven data collectors (2 health officers, 2 clinical nurses and 2 laboratory technicians) and one supervisor (health officer) were recruited and participated in the study. Only urine sample was taken from each child, and a home visit was made to gather the rest of the information from the mother/care giver of the child.

To ensure consistency, the English version of the questionnaire was translated into Afan-Oromo (the native language of the study area) and then back translated to English by English language and public health experts. Two days of training was given to data collectors and supervisors. The training mainly focused on equipping the trainees on the objective of the study, technique of interview, collection of samples, and maintaining of ethical issues. The data collection tool was pretested on $5 \%$ of the study subjects out of the selected schools. During the pretest, the acceptability and applicability of the procedures and tools were evaluated. All questioners were regularly checked for completeness, clarity, and consistency by the field supervisor. Furthermore, the investigators coordinated the overall data collection activities.

\section{Measurements}

In cases of individuals with normal physiological functions, about $90 \%$ of body iodine is excreted through urine; as a result estimating the median urine iodine level is supposed to be an important indicator of the burden of ID for the entire population [5]. Also, it has been considered as the most reliable measure of the current iodine intake [13]. Mindful of the established facts in determining the urinary iodine level, we took 5$10 \mathrm{ml}$ of urine sample from each child, and collected it in a properly labeled and sterilized screw caped plastic bottle. The sample was kept at $4{ }^{\circ} \mathrm{C}$ in a refrigerator with 
all precautionary measures until analysis. The urinary iodine level was analyzed based on the ammonium per sulfate method [31] in the Ethiopian Health and Nutrition Research Institute (EHNRI), and the result was expressed in micrograms of iodine per $100 \mathrm{ml}$ of urine. Finally, the iodine status of the child was interpreted as severe ID if the urine iodine level was $<20 \mu \mathrm{g} / \mathrm{l}$, while the participant was deemed to have a moderate and mild ID if their urine iodine level ranged from $20-49.9 \mu \mathrm{g} / \mathrm{l}$ and $50-99.9 \mu \mathrm{g} / \mathrm{l}$, respectively. Additionally, a child was said to have adequate or sufficient iodine status if its iodine level was between 100 and $199.9 \mu \mathrm{g} / \mathrm{l}$, but having a urinary iodine level of $200-300 \mu \mathrm{g} / \mathrm{l}$ and $>300 \mu \mathrm{g} / \mathrm{l}$ was declared as an excessive level of iodine in the body [5].

The inspection and palpation of the thyroid gland provides information about the size (enlargement), consistency, and surface of the thyroid [8]. As a result, physical examination was performed by trained health officers to determine the size of the thyroid gland. Goiter was clinically defined according to the WHO criteria: grade-0 (no palpable goiter), grade-1 (palpable and visible goiter with extended neck), and grade-2 (visible goiter with the head in normal position) [10].

Regarding the determination of salt iodine content, the data collectors took the sample of salt used for cooking at the study participants home. Kit on spot was used to determine the iodine content of the salt, and it contains a small white cup, two test solution ampoules of $10 \mathrm{ml}$, and a recheck solution ampoule of $10 \mathrm{ml}$. In addition, it has a color chart indicators for iodine content showing a $0 \mathrm{ppm}$, less than $15 \mathrm{ppm}$, and $\geq 15 \mathrm{ppm}$. The small cup in the kit was filled with salt and made the cup surface flat. The two drops of properly shacked test solutions were added on the surface of the salt by piercing the white ampoule with a pin and gently squeezing the ampoule. The iodine content of salt was determined after 1 min by comparing the color developed on the salt with the chart color. If no color appears after $1 \mathrm{~min}, 5$ drops of the recheck solution were added in the red ampoule containing a fresh salt sample spot, and then 2 drops of test solution on the same spot. Finally, the color of the sample was compared with the chart color and the salt iodine content was ascertained using this color result [10].

The standardized Individual Dietary Diversity Score tool tailored from the Food and Nutrition Technical Assistance (FANTA 2011) was used to qualitatively assess the dietary intake of children. The tool contained nine food groups, and it was aimed to reflect the micronutrient adequacy of the diet [32]. Mothers/guardians were requested to list the food consumed by the children in the previous $24 \mathrm{~h}$ preceeding the date of survey, and the reported food items were categorized into the nine food groups. The final DDS containg a maximum of nine
Table 1 Socio-demographic and economic characteristics of school children and their parents in Robe District, southeast Ethiopia, 2015

\begin{tabular}{|c|c|c|}
\hline Characteristics & Frequency & Percent \\
\hline \multicolumn{3}{|l|}{ Sex of the child } \\
\hline Male & 177 & 45.0 \\
\hline Female & 216 & 55.0 \\
\hline \multicolumn{3}{|c|}{ Age of the child (in years) } \\
\hline $6-9$ & 223 & 46.7 \\
\hline $10-12$ & 170 & 43.3 \\
\hline \multicolumn{3}{|l|}{ Religion } \\
\hline Orthodox & 181 & 46.1 \\
\hline Muslim & 198 & 50.4 \\
\hline Others $^{a}$ & 14 & 3.5 \\
\hline \multicolumn{3}{|l|}{ Ethnicity } \\
\hline Oromo & 352 & 89.6 \\
\hline Other ${ }^{b}$ & 41 & 10.4 \\
\hline \multicolumn{3}{|c|}{ Mother's education } \\
\hline Illiterate & 37 & 9.4 \\
\hline Literate & 356 & 90.6 \\
\hline \multicolumn{3}{|c|}{ Mother's employment } \\
\hline Employed $^{c}$ & 92 & 23.4 \\
\hline Housewife & 198 & 50.4 \\
\hline Daily laborer & 47 & 12.0 \\
\hline Merchant & 56 & 14.2 \\
\hline \multicolumn{3}{|c|}{ Father's education } \\
\hline Illiterate & 19 & 4.8 \\
\hline Literate & 374 & 95.2 \\
\hline \multicolumn{3}{|c|}{ Father's employment } \\
\hline Employed $^{c}$ & 103 & 26.2 \\
\hline Farmer & 95 & 24.2 \\
\hline Daily laborer & 58 & 14.8 \\
\hline Merchant & 137 & 34.8 \\
\hline \multicolumn{3}{|l|}{ Household Size } \\
\hline$\leq 5$ & 110 & 28.0 \\
\hline$>5$ & 283 & 72.0 \\
\hline \multicolumn{3}{|c|}{ Household monthly income (Eth. birr) } \\
\hline$<500$ & 89 & 22.6 \\
\hline $500-1500$ & 98 & 25.0 \\
\hline$\geq 1500$ & 206 & 52.4 \\
\hline
\end{tabular}

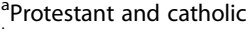

${ }^{\mathrm{b}}$ Amhara, Gurage, Wolayita, Tigre

'Governmental and nongovernmental employe

scores was classified into three categories as poor, medium, and high dietary diversity when the child was served with a diet containing $\leq 3,4-5$, and $\geq 6$ food groups, respectively [32]. 
Table 2 Feeding pattern, hygiene and sanitation related characteristics of school children in Robe District, southeast Ethiopia, 2015 ( $n=393)$

\begin{tabular}{|c|c|c|}
\hline Characteristics & Frequency & Percen \\
\hline \multicolumn{3}{|l|}{ Having regular meals } \\
\hline Yes & 331 & 84.2 \\
\hline No & 62 & 15.8 \\
\hline \multicolumn{3}{|l|}{ Skipping regular meals } \\
\hline Yes & 131 & 33.3 \\
\hline No & 264 & 66.7 \\
\hline \multicolumn{3}{|l|}{$\begin{array}{l}\text { The reasons for skipping regular } \\
\text { meals }(n=129)\end{array}$} \\
\hline Shortage of food & 61 & 47.3 \\
\hline Lack of appetite & 30 & 23.3 \\
\hline Sickness & 38 & 29.4 \\
\hline \multicolumn{3}{|l|}{$\begin{array}{l}\text { The first served child within } \\
\text { a household }\end{array}$} \\
\hline Female & 85 & 21.6 \\
\hline Male & 20 & 5.1 \\
\hline Together & 288 & 73.3 \\
\hline \multicolumn{3}{|l|}{ Type of food commonly consumed } \\
\hline Left over & 96 & 24.4 \\
\hline Fresh & 297 & 75.6 \\
\hline \multicolumn{3}{|l|}{ Water treatment habit } \\
\hline Yes & 23 & 5.9 \\
\hline No & 369 & 93.8 \\
\hline Don't Know & 1 & 0.3 \\
\hline \multicolumn{3}{|c|}{ Method of water treatment $(n=23)$} \\
\hline Boiling & 14 & 60.9 \\
\hline Solar disinfection & 7 & 30.4 \\
\hline Others $^{a}$ & 2 & 8.7 \\
\hline \multicolumn{3}{|l|}{ Availability of home grading } \\
\hline Yes & 113 & 28.8 \\
\hline No & 280 & 71.2 \\
\hline \multicolumn{3}{|c|}{$\begin{array}{l}\text { Types of food staffs cultivated in the } \\
\text { home garden }(n=113)\end{array}$} \\
\hline Fruits & 50 & 44.3 \\
\hline Vegetables & 19 & 16.8 \\
\hline Fruits and vegetables & 44 & 38.9 \\
\hline \multicolumn{3}{|c|}{ Purpose of home gardening $(n=113)$} \\
\hline For household consumption & 72 & 63.7 \\
\hline For market & 4 & 3.5 \\
\hline $\begin{array}{l}\text { For market and household } \\
\text { consumption }\end{array}$ & 37 & 32.8 \\
\hline \multicolumn{3}{|l|}{ Availability of latrine } \\
\hline Yes & 392 & 99.7 \\
\hline No & 1 & 0.3 \\
\hline
\end{tabular}

Table 2 Feeding pattern, hygiene and sanitation related characteristics of school children in Robe District, southeast Ethiopia, 2015 ( $n=393$ ) (Continued)

\begin{tabular}{lll}
\hline Type of latrine & & \\
Flush toilet & 8 & 2.0 \\
Pit latrine & 192 & 48.9 \\
Pit latrine without slab & 193 & 49.1 \\
\hline
\end{tabular}

${ }^{a}$ Adding chemical and water agar

\section{Statistical analysis}

Data were entered into Epi-info version 3.5.3 and analyzed using Statistical Package for Social Sciences (SPSS) version 20. Descriptive statistics, including frequencies and proportions were used to summarize variables. A bivariable analysis was carried out to see the crude effect of each independent variable on ID (urinary iodine level of $<100 \mu \mathrm{g} / \mathrm{l}$ ). Variables with a $P$ values of $<0.2$ were entered into the multivariable logistic regression analysis. Both Crude Odds Ratio (COR) and Adjusted Odds Ratio (AOR) with a corresponding $95 \%$ Confidence Interval (CI) were computed to show the strength of the association. In the adjusted analysis, a $P$-value of $<0.05$ was used to declare statistical significance.

\section{Results}

A total of 393 children participated in the study giving a response rate of $93.1 \%$. The mean ( \pm Standard Deviation, SD) age of the children was $9.15( \pm 1.6)$ years and nearly two-third (46.7\%) were aged 6-9 years. About two-third $(72.0 \%)$ of the children had more than five family size members. Almost all of the mothers (90.6\%) and fathers (95.2\%) were literate (Table 1$)$.

The majority $(84.2 \%)$ of children had three regular meals per day, while about $75.6 \%$ were served fresh food (Table 2). The dietary pattern of the majority of children were largely based on cereals (91.9\%), and legumes (74.3\%), followed by vegetables $(63.9 \%)$ and dairy products $(59.9 \%)$. However, the consumption of animal food products was low, in which about one-quarter (25.7, and $23 \%$, respectively) of children ate meat and egg. Only few, $4.8 \%$, of them ate fish in the past 24-h (Fig. 1). Almost all (99.7 \%) of the parents had private latrine, and accessed water from safe sources (91.7\%). Approximately one-third $(28.8 \%)$ of the parents had home gardening for fruit and vegetables (Table 2).

In this study, the median urine iodine level was $78 \mu \mathrm{g} /$ l, and about $57 \%$ [95 \% CI: 48.0, $66.0 \%$ ] of the children had low urine iodine level $(<100 \mu \mathrm{g} / \mathrm{L})$, suggesting ID. Out of the children with ID, nearly half (42\%) had a urine iodine level of 50-99 $\mu \mathrm{g} / \mathrm{l}$, whereas about 3.3 and $11.7 \%$ had urinary iodine level of $<20 \mu \mathrm{g} / \mathrm{l}$ and 20 $49 \mu \mathrm{g} / \mathrm{l}$, respectively. 


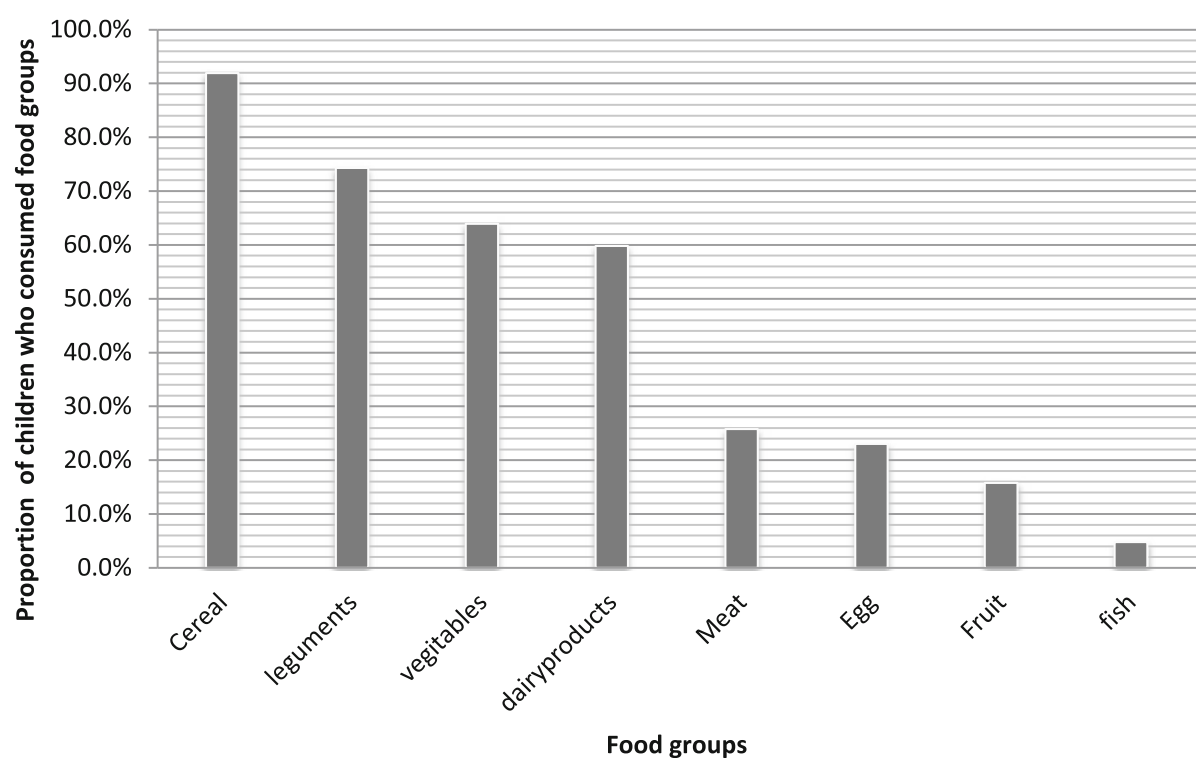

Fig. 1 Proportion of school children (6-12 years) consumed food groups in the last $24 \mathrm{~h}$ preceding the date of survey, Robe District, Southeast Ethiopia, 2015

In addition, the overall prevalence of goiter was $43.5 \%$ [95 \% CI: 33.9, $53.1 \%$ ], in which about 31.3 and $12.2 \%$ were found with grade 1 and grade 2 goiter, respectively. However, only $29 \%$ of the households had adequately iodized salt. Of those households with inadequately iodized salt $(71 \%)$, about 2 and $69 \%$ of the sampled salts were found with ' 0 'ppm and ' $<15$ ' ppm, respectively.

Both the bivariate and multivariate logistic regression analyses were carried out to identify the determinants of ID (urinary iodine level $<100 \mu \mathrm{g} / \mathrm{l}$ ). Accordingly, the result of the bivariate logistic regression analysis showed that age and sex and educational status of the father were significantly associated with ID. However, in the multivariate logistic regression analysis, age and sex of the child remained significantly and independently associated with ID. Consequently, the odds of ID among children aged $10-12$ years were 2.1 times $[\mathrm{AOR}=2.1$; $95 \%$ CI: 1.44, 3.42] higher as compared to children aged 6-9 years. Likewise, the likelihood of ID among male children was 2.2 times [AOR $=2.2$; $95 \%$ CI: 1.54, 3.55] higher than that of female counterparts (Table 3 ).

\section{Discussion}

The median urine iodine concentration of $\geq 100 \mathrm{ug} / \mathrm{l}$ defines a population with no ID [5], however, the present study showed that the median urine iodine concentration among school children was $78 \mu \mathrm{g} / \mathrm{l}$. The finding was in line with what was reported from India $(70 \mu \mathrm{g} / \mathrm{l})$ [33]. But, it is lower than the WHO/UNICEF/ICCIDD jointly recommended cutoff point ( $\geq 100 \mathrm{ug} / \mathrm{l})$ [5] and, reports from India, such as Uttarakhand $(125 \mu \mathrm{g} / \mathrm{L})$ [34] and
Table 3 Factors associated with iodine deficiency (urine iodine level $<100 \mu \mathrm{g} / \mathrm{l}$ ) among school children (6-12 years), Robe District, southeast Ethiopia, 2015 ( $n=393$ )

\begin{tabular}{|c|c|c|c|c|}
\hline \multirow[t]{2}{*}{ Characteristics } & \multicolumn{2}{|c|}{ lodine deficiency } & \multirow[b]{2}{*}{$\begin{array}{l}\mathrm{COR}^{\mathrm{a}} \\
(95 \% \mathrm{Cl})\end{array}$} & \multirow[b]{2}{*}{$\begin{array}{l}\text { AOR } \\
(95 \% \mathrm{Cl})\end{array}$} \\
\hline & Yes (\#) & No (\#) & & \\
\hline \multicolumn{5}{|l|}{ Sex of the child } \\
\hline Male & 80 & 97 & 1 & 1 \\
\hline Female & 144 & 72 & $2.4(1.6,3.5)$ & $2.2(1.5,3.6)^{*}$ \\
\hline \multicolumn{5}{|l|}{ Age of the child (in Years) } \\
\hline $6-9$ & 110 & 113 & 1 & 1 \\
\hline $10-12$ & 114 & 56 & $2.2(1.4,3.4)$ & $1.9(1.2,3.1)^{*}$ \\
\hline \multicolumn{5}{|l|}{ Father's education } \\
\hline Illiterate & 12 & 7 & 1 & \\
\hline Literate & 212 & 162 & $1.3(0.6,8.9)$ & \\
\hline \multicolumn{5}{|l|}{ Mother's education } \\
\hline Illiterate & 26 & 11 & $1.9(0.7,11.1)$ & \\
\hline Literate & 199 & 157 & 1 & \\
\hline \multicolumn{5}{|l|}{ Skipping regular meal } \\
\hline Yes & 79 & 52 & $1.2(0.3,2.4)$ & \\
\hline No & 145 & 117 & 1 & \\
\hline \multicolumn{5}{|l|}{ Salt iodine content } \\
\hline Inadequately iodized & 154 & 125 & 1 & \\
\hline Adequately iodized & 70 & 44 & $1.3(0.8,3.1)$ & \\
\hline
\end{tabular}

${ }^{*} P<0.05$

${ }^{a}$ Crude Odds Ratio

${ }^{\mathrm{b}}$ Adjusted Odds Ratio 
India $(165 \mu \mathrm{g} / \mathrm{L}, 235 \mu \mathrm{g} / \mathrm{L})$ [35]. On the other hand, about $57 \%$ children had low urine iodine level $(<100 \mathrm{ug} / \mathrm{l})$ suggesting the presence of ID. This prevalence was in agreement with the report from South Tajiksitan (51.2 \%) [36]. The difference in the median urinary iodine level between the current and the former study settings might be related to poor dietary intake of iodine rich food and low utilization of iodized salt in the study area.

This study also demonstrated that utilization of iodized salt $(29.3 \%)$ was lower than the WHO recommendation (>90\%) [5], and other African countries, like South Africa (62.4\%), Uganda (96 \%), Ghana (75.6 \%), and South Sudan (72.9 \%) [5]. However, there was a bit improvement as compared to previous local reports, such as the 2011 Ethiopian Demographic and Health Survey Report (13.3 \%) [27], Somali Region (7.7 \%) [28], and Tigray Region (22.3\%) [20]. This improvement in utilization of iodized salt could be related to the current efforts of the government in implementing the already available programs designed to promote the production and distribution of iodized salt [37-40].

According to WHO criteria, ID is considered as a public health problem if the total goiter rate is $>5 \%$ [2]. However in this study setting, the prevalence of goiter was found to be $43.5 \%$, which confirmed that there is a severe public health problem. Likewise, the current prevalence was higher than the study reports of other developing countries, including Mandy (6.6 \%) [25] and Amreli districts, India (25.2 \%) [23], Pakistan (10 \%) [29], Tanzania (22 \%), and Ecuador (30 \%) [6].

The prevalence of goiter was lower than previous study reports in Ethiopia; for example Southern Ethiopia (56.2 \%) [30], Jimma, southwest Ethiopia (59.1 \%) [14], Neksege, northern Ethiopia (71.4 \%) [20], and Womberma and Burie, northwest Ethiopia (54\%) [31]. The discrepancy could be attributed to the current improvements in utilization of iodized salt compared to the periods the other studies were conducted.

The result of the adjusted analysis showed the increased odds of ID among children aged 10-12 years compared to children aged 6-8 years. The finding was supported by other studies conducted elsewhere [23, 31-33]. Obviously, iodine requirement increases with age. Because of pubertal growth spurt and intense anabolic period, children aged 10-12 had higher iodine requirements to support their rapid growth as compared to children aged 6-9 years [34]. In addition, this life stage, 10-12 years, is a part of adolescence where $20 \%$ of adult height and $50 \%$ of adult weight are attained [35].

Likewise, the higher odds of ID were observed among female children compared to their male counterparts. This report is in line with previous findings elsewhere $[6,17,23,24,26,35,36,41,42]$. This might be due to a higher iodine requirement of females to support their growth and development [35]. Furthermore, a female hormone (estrogen) has an inhibitory effect on iodine uptake by the thyroid follicular cells [22].

The study showed the magnitude of ID using biochemical and clinical assessment methods, which helps to better understand the problem in the study area. In addition, the utilization of iodized salt was estimated. However, the study is not free from some of limitations. Firstly, only school children were included in this study, where the result may not be generalizable to outschool children. Secondly, hence the study employed a crosssectional study design, the findings may not show the cause and effect relationship between iodine deficiency and the independent variables.

\section{Conclusion}

In this study, the prevalence of ID (goiter and low urine iodine level) was high, suggesting a severe public health problem. Lower utilization of iodized salt was also documented in the setting. Furthermore, the higher odds of ID was observed among older aged (10-12 years) and female children. Therefore, there is a need to intensify the implementation of universal salt iodization and attention should be given to school children to efficiently address ID.

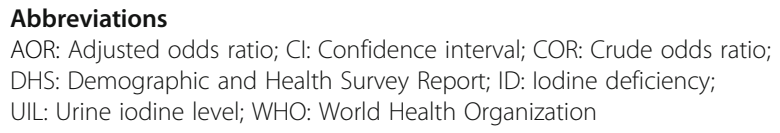

\section{Acknowledgment}

The authors would like to express their sincere gratitude to the study subjects for their willingness to participate. Their heartfelt thanks also go to Madawalabu University for the financial support.

\section{Funding}

No funding was obtained for this study.

\section{Availability of data and materials}

All the required data will be made available upon request of the primary author.

\section{Authors' contributions}

Conceived and designed the experiments: SH, AT, MW. Performed the experiments: SH, AT. Analyzed the data: SH, AT, HW. Wrote the paper: SH, AT, MW, HW. Approved the proposal with some revisions: SH, AT, MW. All authors read and approved the final manuscript.

\section{Competing interests}

The authors declare that they have no competing interests.

\section{Consent to publish}

Not applicable.

Ethical approval and consent to participate

The study was ethically approved by the Ethical Review Board of the University of Gondar, Gondar, Ethiopia. Permission letter was secured from the Oromia Health Bureau, Bale Zonal Health Department and Robe District Health Office. The purpose of the study was explained, and individual assent and written parental consent was secured from each study participant. The right of a participant to withdraw from the study at any time, without any precondition was disclosed unequivocally. Moreover, the confidentiality of 
information obtained was guaranteed by all data collectors and investigators using code numbers rather than personal identifiers and by keeping the questionnaire locked.

\section{Author details}

${ }^{1}$ Department of Public Health, College of Medicine and Health Sciences, Madawalabu University, Goba, Ethiopia. ${ }^{2}$ Department of Environmental and Occupational Health and Safety, College of Medicine and Health Sciences, Institute of Public Health, University of Gondar, Gondar, Ethiopia.

${ }^{3}$ Department of Human Nutrition, Institute of Public Health, College of Medicine and Health Sciences, University of Gondar, Gondar, Ethiopia.

Received: 27 April 2016 Accepted: 9 October 2016 Published online: 31 October 2016

\section{References}

1. Sen S, Sen S, Mondal A, Dasgupta A, Chakraborty I. Prevalence of iodine deficiency disorders among schoolchildren in three blocks of Bardhaman District and Bardhaman Municipal area of West Bengal, India: a comparative study. Southeast Asian J Trop Med Public Health. 2005;36(5):1321.

2. WHO. Assessment of iodine deficiency disorders and monitoring their elimination: a guide for programme managers. 2007.

3. Padilla CD, Fagela-Domingo C. Eliminating iodine deficiency: obstacles and their removal. Ann Acad Med Singapore. 2008;37(3):45-8

4. Egli IM, Allen H, El Bahi T, Andersson M, De Benoist B, World Health Organization. lodine status worldwide: WHO global database on iodine deficiency. 2004

5. WHO. Urinary iodine concentrations for determining iodine status deficiency in populations. Vitamin and Mineral Nutrition Information System. Geneva: World Health Organization; 2013.

6. WHO. ICCIDD (2001) Assessment of iodine deficiency disorders and monitoring their elimination. A guide for programme managers. Geneva: World Health Organization; 2007.

7. Andersson M, Karumbunathan V, Zimmermann MB. Global iodine status in 2011 and trends over the past decade. J Nutr. 2012;142(4):744-50.

8. Benoist B, McLean $E$, Andersson M, Rogers L. lodine deficiency in 2007: global progress since 2003. Food Nutr Bull. 2008;29(3):195-202.

9. Hofvander $Y$. Endemic goitre among children in the Ethiopian highlands. Effect of a supplementary food with iodized salt. Ethiop Med J. 1970;8(4):179-84.

10. Molineoux L, Ayele T. Endemic goitre surveys in Begemidir province, Ethiopia. Eth Med J. 1967;1:239.

11. Wolde-Gebriel Z, Demeke T, West CE, Van der Haar F. Goitre in Ethiopia. Brit J Nutr. 1993;69:257-68.

12. Abuye C, Ayana G, Umeta M, Tibeb HN, Hailemariam B. Thyroid responses to varying doses of oral iodized oil in school children in Awassa, Ethiopia. Ethiop J Health Dev. 2000;14(1):49-55.

13. Cherinet A, Kelbessa U. Determinants of iodine deficiency in school children in different regions of Ethiopia. East Afr Med J. 2000;77(3):133-7.

14. Mezgebu Y, Mossie A, Rajesh P, Beyene G. Prevalence and severity of iodine deficiency disorder among children 6-12 years of age in Shebe Senbo District, Jimma Zone, Southwest Ethiopia. Ethiopian Journal of Health Sciences. 2012;22(3):196-204

15. Shawel D, Hagos S, Lachat CK, Kimanya ME, Kolsteren P. Post-production losses in iodine concentration of salt hamper the control of iodine deficiency disorders: a case study in northern Ethiopia. J Health Popul Nutr. 2010;28:238-44.

16. Delange F. The disorders induced by iodine deficiency. Thyroid. 1994; 4(1):107-28

17. Ugo J, Chinwe E. A pilot study of iodine and anthropometric status of primary school children in Obukpa, a rural Nigerian community. Journal of Public Health and Epidemiology. 2012;4(9):246-52.

18. Gidey B, Alemu K, Atnafu A, Kifle M, Tefera Y, Sharma H. Availability of adequate iodized salt at household level and associated factors in rural communities in Laelay Maychew District, Northern Ethiopia: a cross sectional study. Journal of Nutrition and Health Sciences. 2015;2(1):1.

19. Gaitan E. Goitrogens in food and water. Annu Rev Nutr. 1990;10(1):21-37.

20. Kidane T, Woldegebriel A. Prevalence of iodine deficiency disorder in a highland district in Tigray. Ethiop J Health Dev. 2006;20(1):58-9.
21. Kennedy G, Ballard T, Dop MC. Guidelines for measuring household and individual dietary diversity: Food and Agriculture Organization of the United Nations; 2011

22. WHO U. ICCIDD. Assessment of iodine deficiency disorders and monitoring their elimination. Geneva: World Health Organization, (WHO/NHD/011); 2001

23. Amin D, Rathod S, Doshi V, Singh M. Changing prevalence of iodine deficiency disorders in Amreli District, Gujarat, India. NJIRM. 2011;2:77-80.

24. Kapil U, Pandey RM, Prakash S, Kabra M, Sareen N, Bhadoria AS. Assessment of iodine deficiency in school age children in Nainital District, Uttarakhand State. Asia Pac J Clin Nutr. 2014:23(2):278.

25. Pushpa S, Harish BR, Aghunath HR, Mahendra BJ, Vinay M, Nimisha V. Prevalence of iodine deficiency disorders among school children aged 6-12 years in Mandya District, Karnataka. International Journal of Scientific Study. 1214;2(8)

26. Matthys B, Davlatmamadova M, Karimova G, Jean-Richard V, Zimmermann $M B$, Wyss K. lodine nutritional status and risk factors for goitre among schoolchildren in South Tajikistan. BMC Endocr Disord. 2013;13(1):1.

27. CSA I. Ethiopia demographic and health survey 2011. Addis Ababa, Ethiopia and Calverton, Maryland, USA: Central Statistical Agency and ICF International; 2012.

28. Kassim A, et al. lodine in take in Somalia is excessive and association with source of house hold drinking water. J Nurti. 2014;144:375-81.

29. Saira S, Khattak R, Rehman A, Khan A, Khattak M. Prevalence of goiter and iodine status in 6-12 years school children and pregnant women of district Charsadda, Pakistan. Acta Endocrinologica (Buc). 2014;10(1):65-75.

30. Berhanu N, Michael KW, Bezabih M. Endemic goiter in school children in Southwestern Ethiopia. Ethiop J Health Dev. 2005;18(3):175-8.

31. Aweke K, Adamu B, Girmay A, Yohannes T, Alemnesh Z, Abuye C. lodine Deficiency Disorders (IDD) in Burie and Womberma Districts, West Gojjam, Ethiopia. Afr J Food Agric Nutr Dev. 2014;14(4):9167-80.

32. Mesele M, Degu G, Gebrehiwot H. Prevalence and associated factors of goiter among rural children aged 6-12 years old in Northwest Ethiopia, cross-sectional study. BMC Public Health. 2014;14(1):1.

33. Hetzel BS, Stanbury J JT. The prevention and control of lodine deliciency disorders. 1987

34. Zimmermann MB. Symposium on 'Geographical and geological influences on nutrition' lodine deficiency in industrialised countries. Proc Nutr Soc. 2010;69(01):133-43.

35. Giuseppina D. Nutrition in adolescence. Pediatr Rev. 2000;21(1):32-3.

36. Kamath R, Bhat V, Rao R, Das A, Ganesh K, Kamath A. Prevalence of goiter in rural area of Belgaum district, Karnataka. Indian J Community Med. 2009;34(1):48

37. Jooste $\mathrm{PL}$, Weight MJ, Lombard CJ. lodine concentration in household salt in South Africa. Bull World Health Organ. 2001;79(6):534-540.

38. Statistics UBo, MEASURE/DHS+ OM: Uganda Demographic and Health Survey, 2006: Uganda Bureau of Statistics; 2007.

39. Buxton C, Baguune B. Knowledge and practices of people in Bia District, Ghana, with regard to iodine deficiency disorders and intake of iodized salt. Archives of Public Health. 2012;70(1):1.

40. Mutwakel Gaffar A, Salih Mahfouz M. Peace impact on health: population access to iodized salt in south Sudan in postconflict period. Croatian Medical Journal. 2011;52(2):178-182.

41. Singh MB, Marwal R, Lakshminarayana J. Assessment of iodine deficiency disorders in school age children in Jodhpur dictrict of Rajasthan. J Hum Ecol. 2010;32(2):79-83.

42. Mousavi S, Tavakoli N, Mardan F. Risk factors for goiter in primary school girls in Qom city of Iran. Eur J Clin Nutr. 2006;60(3):426-33. 